\title{
Long-Term Changes in Night Time Airglow Emission at 557.7 nm over Mid Latitude Japanese Station i.e., Kiso $\left(35.79^{\circ} \mathrm{N}, 137.63^{\circ} \mathrm{E}\right)$
}

\author{
Brij Mohan Vyas ${ }^{1}$, Vimal Saraswat ${ }^{1,2}$ \\ ${ }^{1}$ Department of Physics, M. L. Sukhadia University, Udaipur, India \\ ${ }^{2}$ Department of Basic Sciences, Pacific College of Engineering, Udaipur, India \\ Email: bmvyas@yahoo.com,vimal_saraswat80@rediffmail.com
}

Received July 21, 2012; revised August 23, 2012; accepted September 12, 2012

\begin{abstract}
The present study describes the long-term changes in Pre-midnight and Midnight airglow intensities of $557.7 \mathrm{~nm}$ during the period 1979-1994 over mid latitude Japanese station i.e., Kiso, Tokyo Astronomical Observatory, University of Tokyo $\left(35.79^{\circ} \mathrm{N}, 137.63^{\circ} \mathrm{E} ; 1130 \mathrm{~m}\right)$, Japan. It has observed that there is a positive increasing decadal change in Midnight and Pre-midnight mesospheric airglow intensity of the range 25 - $88 \mathrm{R}$. This range is the order of $10 \%$ to $30 \%$ of the observed MARV and average night airglow intensity of $250 \mathrm{R}$. Besides this long-term trend, inter-annual monthly variation is also seen from fluctuation of yearly variation of deviation values from MARV to particular average monthly values. The present observations about the positive decadal change in night time mesospheric airglow intensity has been further linked to the reduction of mesospheric electron densities and temperature or shrinking and cooling of the lower ionosphere as established from the long-term behavior of mesospheric parameters such as a negative decadal change in thermal structure, electron density, neutral density parameters as per studies reported by other researchers.
\end{abstract}

Keywords: Airglow; Long-Term Changes; Ionosphere

\section{Introduction}

The ionosphere of Earth emits electromagnetic radiation spectrum ranging from the visible to near infrared (IR) wavelength during different hours continuously. These radiations depend on neutral \& electron density, temperature, rate of the recombination and photochemical reactions between numerous chemical species occurring at different altitudes of ionospheric layers [1,2]. It is fact that about $40 \%$ of the light in a dark moonless night, beyond the city comes not from the stars or zodiacal belt or galaxies, it scattered by atmospheric particles. The natural chemi-luminescence's process in the presence of numerous types of atmospheric atoms and molecules present in earth's ionosphere produce this light [3]. This weak self-luminescence activity observed on the ground is known as Airglow [4]. In simple way the glowing of air is termed as airglow. The airglows are mainly of three types like day, twilight and night airglow according to their time of occurrences [5].

During daytime, the atmospheric atoms, molecules and ions get excited by absorbing incidental solar energy fluxes and subsequently they come down to the ground state, emitting energy as light and it is termed as Day Airglow [1,6,7]. However, in night hours, when they come down to ground state or meta-stable lower energy state, they emit the electromagnetic radiation light; these transitions known as Night Airglow. In addition to this, collision also plays a vital role for night airglow emission. During twilight hours, the ions, atoms and molecules are partly or completely getting excited not only by absorbing solar energy but also by different collision phenomenon. The various types of airglow spectrums are such as lines, band and continuum type of emission ranging from ultraviolet (UV) to near IR. The primary emission lines, accessible on the grounds are known as Oxygen airglow (OI $557.7 \mathrm{~nm}$ (Green), OI $630 \mathrm{~nm}$ (Red)), Hydroxyl airglow and Sodium D-airglow lines (Na-D 589.3 $\mathrm{nm}$ (Yellow)) [8].

There are several lines of wavelengths concerned to different ionospheric regions of night airglows. Generally night airglow of Na-D line $(589.3 \mathrm{~nm})$ is found to be linked with mesospheric-lower thermospheric (MLT) region i.e., 90 to $100 \mathrm{~km}$ (peak emission altitude $\sim 92 \mathrm{~km}$ ), whereas the night airglow of deep red emission at 630 $\mathrm{nm}$ (peak emission altitude $\sim 250 \mathrm{~km}$ ) attributes to ionospheric F-region [9]. However, the nocturnal airglow intensity at $557.7 \mathrm{~nm}$ is mainly concerned with the mesospheric region in different night hours $[8,10,11]$. Thus, nocturnal airglow intensity of OI $557.7 \mathrm{~nm}$, Na-D 589.3 
$\mathrm{nm}$ and OI $630 \mathrm{~nm}$ are concerned with mesospheric, mesospheric-lower thermospheric and thermospheric regions respectively.

In the mesosphere OI green line emission at $557.7 \mathrm{~nm}$ arising from the $\mathrm{O}\left({ }^{1} \mathrm{~S}-{ }^{1} \mathrm{D}\right)$ transition have one of the prominent night airglow features. The production of the excited oxygen atom $\mathrm{O}\left({ }^{1} \mathrm{~S}\right)$ of energy $4.2 \mathrm{eV}$ was first proposed by Chapman in terms of a three body recombination of O atoms [12]. Later, Barth [13] proposed a twostep mechanism involving an excited state of $\mathrm{O}_{2}$, which favored by various measurements. These atmospheric chemical reactions with catalyst mechanism involve the following steps:

$$
\begin{aligned}
& \mathrm{O}+\mathrm{O}+\mathrm{M} \rightarrow \mathrm{O}_{2}^{*}+\mathrm{M} \\
& \mathrm{O}+\mathrm{O}_{2}^{*} \rightarrow \mathrm{O}\left({ }^{1} \mathrm{~S}\right)+\mathrm{O}_{2}
\end{aligned}
$$

Several researchers have described the short-term variations such as nocturnal hourly variation, seasonal dependence of night time airglow intensities since last decades [3-5] and an excellent review works was given by Chattopadhyay and Midya [2].

In this direction, some typical investigations were reported on the Thermospheric airglow studies, concerned with the interrelation among some of ionospheric F-region parameters such as the Maximum Electron density of F-region $\left(\mathrm{N}_{\mathrm{m}} \mathrm{F} 2\right)$, Critical Frequency $\left(\mathrm{f}_{0} \mathrm{~F}_{2}\right)$, Virtual Height (h'F), Total Electron Content variables as well as precursors of Spread-F with the airglows emission at 630 nm $[11,14,15]$. Thus, the optical emissions of the night airglow intensity investigation plays a vital role in understanding the short as well as long-term changes in neutral and thermal properties of different ionospheric regions through the collision, quenching and photochemical reactions in the upper and lower ionosphere. Hence, it is very useful as a proxy for monitoring of long and short-term variations in neutral density and thermal properties of the ionosphere during different space weather phenomena and in normal solar geophysical environment.

In these perspectives of long-term trends, Jana \& Nandi [16-19] and Jana et al. [3,20], have performed the analysis specifically based on computed long-term night airglow intensity at $589.3 \mathrm{~nm}$ at some of Indian stations and reported the close association of long-term change in MLT Airglow intensities with depletion of long-term trend in ozone. Similarly Vyas \& Saraswat [21] on the basis of observed data of Na-D airglow of the present study site i.e., Kiso (Japan) reported a declining longterm trend in ozone value and mesospheric temperature or ozone depletion and mesospheric cooling phenomena. The first critical review work on the long-term in mesospheric temperature trend on earlier reported observations were summarized and discussed by Beig et al. [22]. They established primary fact about the evidences of long-term mesospheric cooling, based on ground, satel- lite and rocket based experiments of the multi decade period atmospheric data set. Sobral et al. [15], have investigated the ionospheric plasma bubbles climatology based on 22 years of $630 \mathrm{~nm}$ airglow observations over Brazil.

Thus, studies of long-term variation on mesospheric airglow specifically based on experimentally observed data and its possible causes are either rare or few [23-25]. Rajesh et al. [23], have reported the ionospheric plasma depletion phenomenon over Kavalur i.e., Indian low latitude station using the nighttime airglow intensity measurements at $557.7 \mathrm{~nm}$. Effect of seasonal, solar cycle variation and determination of different range of periodicities from a few days to less than one solar cycle on nighttime airglow intensity of $557.7 \mathrm{~nm}$ over Kiso, was also described by Das et al. [24,25]. But earlier workers have not attempted to such rare studies on long-term trend behavior on nighttime airglow emission intensity at $557.7 \mathrm{~nm}$. Realizing these facts in mind, an attempt has been made in the present paper to study the long-term change on the basis of experimentally measured nighttime airglow intensities $557.7 \mathrm{~nm}$, which were recorded for the period 1979-1994 over mid latitude Japanese stations Kiso, Tokyo Astronomical Observatory (TAO), University of Tokyo $\left(35.79^{\circ} \mathrm{N}, 137.63^{\circ} \mathrm{E} ; 1130 \mathrm{~m}\right)$, Japan. Such long time series data are available only on the study site, so this particular station has been taken for the work.

\section{Data Analysis}

The basis of the present analysis is regular observations of oxygen (OI) airglows brightness at zenith (3 degrees diameter) on moonless clear night days. The present investigation is carried out from the analysis of data set of hourly values of night airglow intensity at $557.7 \mathrm{~nm}$ recorded over Kiso, TAO, Japan. These daily hourly time series have downloaded from the Solar Activity World Data Center, Japan from the web site (http://solar www. mtk.nao.ac.jp/wdc.html) during the period 1979-1994. Such extensive data cover almost one and half solar cycle and therefore provide an opportunity to carry out long-term trend study analysis over mid latitude airglow emission at $557.7 \mathrm{~nm}$, which primarily refers to a mesospheric region [2].

To ascertain the long-term trend first, it is necessary to remove hourly, seasonal and solar cycle variation of the airglows intensities from the available raw time series data. In this connection, following method has adopted in the present course of work.

\section{Method of Analysis}

First, average monthly airglow intensity values have computed for three hours intervals between 20:00 to 22:00 hours as Pre-midnight period and 23:00 to 01:00 
hours as the Midnight period from their respective daily values of each particular month of the years (1979-1994). The particular average monthly values of Pre-midnight and Midnight hours have been computed to eliminate the hourly, month-to-month as well as seasonal dependence factors from the raw daily airglow data. Subsequently, monthly average reference value (MARV) has also calculated separately from the average monthly values of Pre-midnight and Midnight hours for each specific month of the entire selected study years. Such MARV value of individual monthly value of airglow intensity is evaluated to eliminate the solar cycle dependence of entire specified period and is shown in the Table 1 and Figures $\mathbf{1}$ and 2. Therefore, MARV has treated as reference value for the specific month of observations of the chosen study period.

The deviation of the individual average monthly values from corresponding MARV of the similar months have computed and plotted as a function of years. The average values of such deviations are also depicted as black dotted lines to visualize the overall long-term trend in Mesospheric airglow intensities or departure from the normal level.

Furthermore, such time series of deviation value of MARV are subjected to statistical linear regression analysis to find the slope or yearly change and correlation coefficient (R') etc., of the linearly fitted line. The statistically linearly regression fitted line as the red line is il lustrated along with their observed trend exhibited by dark black line in the same figures (Figures $\mathbf{1}$ and 2). The slope, $\mathrm{R}$ ' and probability (P) values have also shown in each figure, which gives the inference about the changing of airglow intensity per year with its statistical significance, respectively. Figures 1 and $\mathbf{2}$ show graphical representations of the long-term change in airglow intensities $557.7 \mathrm{~nm}$ in each individual month of years from
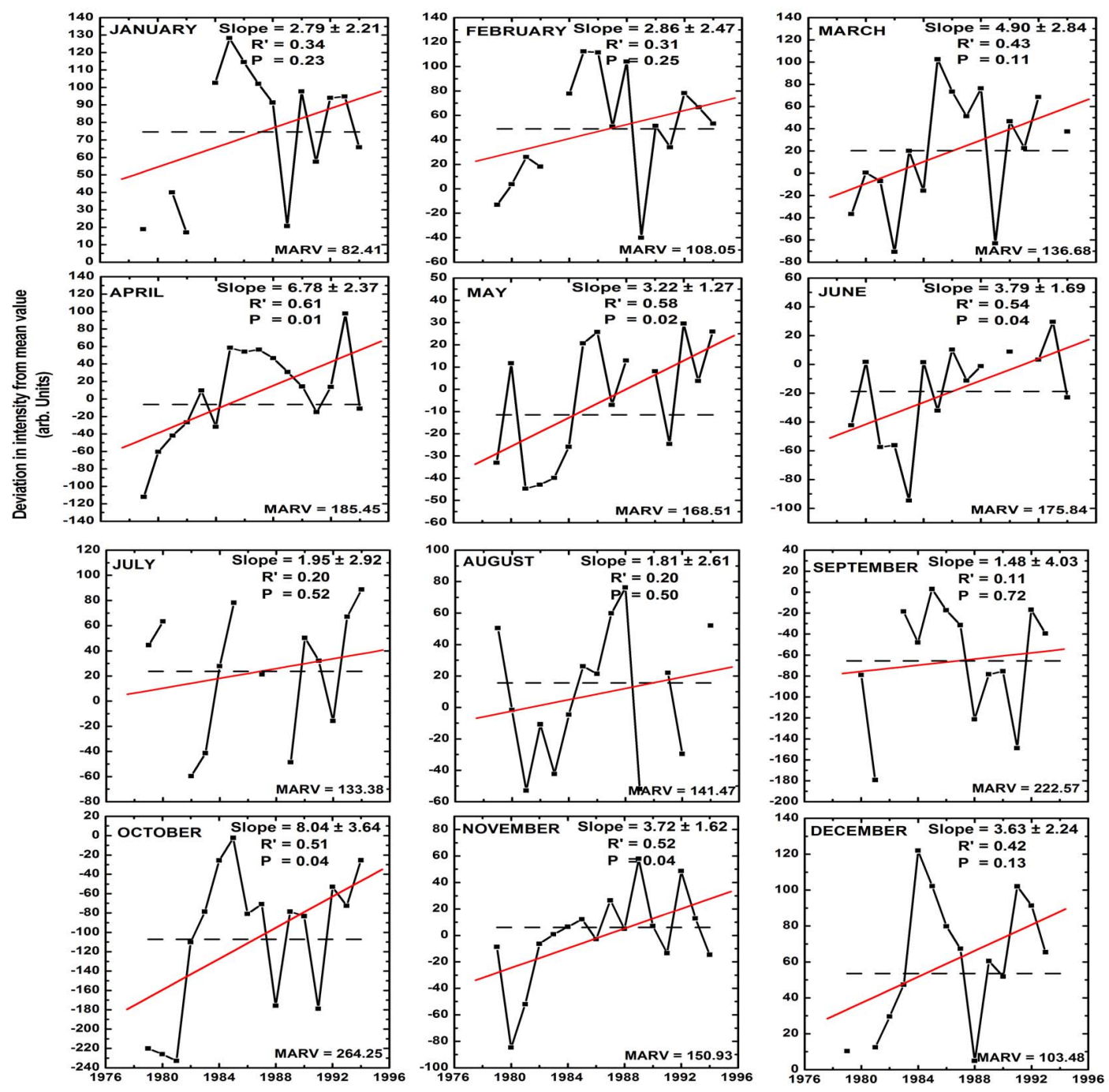

Figure 1. Long-term change in pre-midnight airglow intensity at $557.7 \mathrm{~nm}$ for different months. 

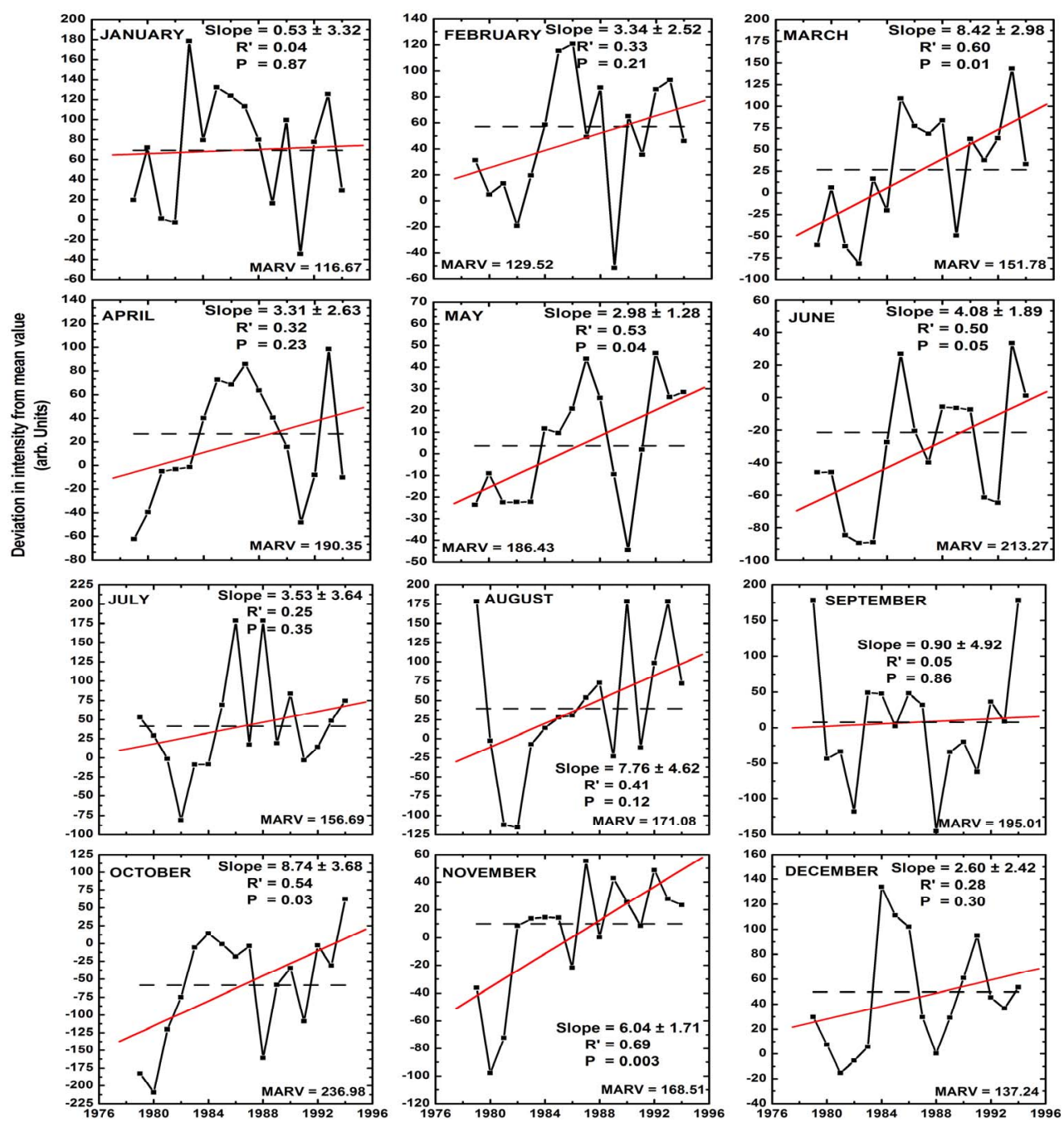

Figure 2. Long-term change in midnight airglow intensity at $557.7 \mathrm{~nm}$ for different months.

1979-1994 for Pre-midnight and Midnight hours respectively. The results obtained from the analysis have presented and discussed in the next section

\section{Results}

\subsection{Mid Latitude Pre-Midnight Airglow Intensities}

Figure 1 represents the year to year variation in deviation values from MARV to its individual particular average monthly value of Pre-midnight green airglow emission of Oxygen on $557.7 \mathrm{~nm}$. It is quite evident from figures as well as calculated slope, $\mathrm{R}^{\prime}$ and $\mathrm{P}$ values that deviation values from the MARV airglow intensity shows the maximum positive decadal change between 32 to $80 \mathrm{R}^{1}$ during March to June and October to December (with a maximum value of $80 \mathrm{R}$ in October) but on the basis of the statistical significance level, the good sig-

${ }^{1}$ Unit of airglow intensity, Rayleigh photons $/ \mathrm{cm}^{2} / \mathrm{sec}$. nificance level above 95\% found during April to June, October and November month. The significance level below 95\% found in March \& December and in January \& February months only about $75 \%$ significance is found during this period $28 \mathrm{R}$ per decade change occurs in deviation in intensity from the mean value of the airglow. While in rest of months like July to September, there is an insignificant statistical change (below 50\%) in yearly variation in such airglow intensity. From the close look to the nature of red and black line in the figures and above discussed results, it implies that the most probable deviation values from the MARV to individual average value exhibit the increasing trend and its magnitude varies between 25 to $80 \mathrm{R}$ per decade in most of the months with the statistical significance level of above $90 \%$ except in July to September. While, MARV values are found to be changed between 82 to $264 \mathrm{R}$ with maximum and minimum in October and January months, respectively. Thus, the results observed in the present work 
Table 1. Monthly average reference values of the airglow intensity of OI $577.7 \mathrm{~nm}$ and their standard error value in pre-midnight and midnight hours of different months during study period.

\begin{tabular}{ccc}
\hline \multirow{2}{*}{ Month } & \multicolumn{2}{c}{ MARV during } \\
\cline { 2 - 3 } & Pre-midnight & Midnight \\
\hline January & $82.41 \pm 10.09$ & $116.67 \pm 13.80$ \\
February & $108.05 \pm 11.65$ & $129.52 \pm 12.57$ \\
March & $136.68 \pm 13.44$ & $151.78 \pm 16.62$ \\
April & $185.45 \pm 27.14$ & $190.35 \pm 25.91$ \\
May & $168.51 \pm 10.97$ & $186.43 \pm 12.52$ \\
June & $175.84 \pm 9.09$ & $213.27 \pm 10.23$ \\
July & $133.38 \pm 13.84$ & $156.69 \pm 11.56$ \\
August & $141.47 \pm 15.28$ & $171.08 \pm 18.04$ \\
September & $222.57 \pm 15.44$ & $195.01 \pm 16.42$ \\
October & $264.25 \pm 18.84$ & $236.98 \pm 19.39$ \\
November & $150.93 \pm 10.91$ & $168.51 \pm 12.75$ \\
December & $103.48 \pm 13.34$ & $137.24 \pm 14.95$ \\
\hline
\end{tabular}

like the variation of MARV follows the same trend as well as comparable values to monthly airglow intensity magnitude with the highest value of airglow intensity observed in October and lowest in January retrieved from several year observations over mid latitude sites by Carovillano and Forbe [26]. They also reported the average value of night airglow of OI $557.7 \mathrm{~nm}$ of order $250 \mathrm{R}$ which are also in the same order as observed in the present investigation of the average value of the MARV value of all months.

With consideration of above reported average nominal value of night time airglow intensity of $557.7 \mathrm{~nm}$ order of $250 \mathrm{R}$, observed change in MARV of individual month and decadal fluctuation range of 25 to $80 \mathrm{R}$, it is imperative that increasing decadal change in the Pre-midnight airglow intensity is seen up to $30 \%$ of the average reference nominal value. Furthermore, the year to year fluctuations in the deviation value of the airglow intensity is also attributed the inter-annual monthly nature as evident from the black dotted line.

\subsection{Mid Latitude Midnight Airglow Intensities}

The Midnight yearly behavior of departure values from the MARV to each specific monthly average value are plotted with years in Figure 2. The positive deviation values per decade are found to be lying in the range between 30 to $88 \mathrm{R}$ (statistically significant at least $90 \%$ or above significance level), which is in the same order as observed for the Pre-midnight period. However, the li- near regression trend line (shown by red colour) and average deviation line (shown by dotted black line) exhibit enhancement trend in the highest range of 60 to $88 \mathrm{R}$ per decade during March, October and November and the lowest range of 30 to $40 \mathrm{R}$ per decade in February, April to July. However, in remaining months there is no significant long-term variation in the same night airglow intensity. The MARV of the different months are also found to be varied from 116 to $236 \mathrm{R}$ with a peak value of $236 \mathrm{R}$ in October and the least value in January as shown in Table 1 and Figure 2. Similar monthly variation in airglow intensity is also observed in Pre-midnight hour case in the present investigation and also reported by several researchers on other stations [3-5,10,11].

On the basis of the above discussed results, it is obvious that there is a remarkable inclination of long-term increasing trend in Pre-midnight as well as Midnight mesospheric airglow intensity of 25 to $80 \mathrm{R}$ in some of months with good statistical significance level above $90 \%$. This rate of increase the airglow of OI $557.7 \mathrm{~nm}$ line intensity per decade is in the magnitude of $10 \%$ to $30 \%$ with the observed MARV as well as average nominal of 250 R. Furthermore, the yearly fluctuations in the difference values of specified month are also illustrating the nature of inter-annual monthly behavior in the airglow intensity.

\section{Summary and Discussions}

The long-term behavior of Pre-midnight and Midnight airglow intensities concerning to mesospheric layers are described in the present work. The present results reveal that there is positive increasing decadal change in Midnight and Pre-midnight mesospheric airglow intensity of the magnitude in the range of 25 to $88 \mathrm{R}$, which is the order of $10 \%$ to $30 \%$ of the observed MARV and average night airglow intensity values of OI $557.7 \mathrm{~nm}$ of 250 $\mathrm{R}$ as reported by Carovillano \& Forbes [26]. It has been well recognized and well established fact that each airglow emission intensity and its width primarily depends on the large number of ionospheric parameters like electron density, temperature profile, the nature of chemical species of the concerned height range of airglow emission lines, where it takes place. On the basis of the above argument, it may be stated that consequence of the increasing of mesospheric airglow intensities may be responsible to alter the mesospheric thermal structure, which further seems the cause of reduction of mesospheric electron density. Therefore, such long-term trend in airglow mesosphere intensity can be further linked to the observed reduction of electron density, shrinking of the ionosphere or in term of negative varying nature of its decadal change in temperature and electron density etc., of concerned ionospheric D-region [23-25]. 


\section{Acknowledgements}

We the authors are grateful to Dr. G. Beig, IITM, Pune, India for scientific advice and suggesting the views for the present carried research work. The authors are also thankful to Head, Department of Physics, M. L. Sukhadia University, Udaipur, India for providing necessary encouragements during investigation.

\section{REFERENCES}

[1] M. H. Rees, "Physics and Chemistry of the Upper Atmosphere,” Cambridge University Press, Cambridge, 1989. doi:10.1017/CBO9780511573118

[2] R. Chattopadhyay and S. K. Midya, "Airglow Emissions: Fundamentals of Theory and Experiments," Indian Journal of Physics, Vol. 80, No. 2, 2006, pp. 115-166.

[3] P. K. Jana, I. Saha and S. Mukhopadhyay, "Long-Term Ozone Decline and Its Effect on Night Airglow Intensity of $\mathrm{Li} 6708 \AA$ at Varanasi $\left(25^{\circ} \mathrm{N}, 83^{\circ} \mathrm{E}\right)$ and Halley Bay (76 $\left.{ }^{\circ} \mathrm{S}, 27^{\circ} \mathrm{W}\right)$," Journal of Earth System Science, Vol. 120, No. 2, 2011, pp. 291-300. doi:10.1007/s12040-011-0047-8

[4] S. K. Midya and D. Midya, "The Effect of Antarctic $\mathrm{O}_{3}$

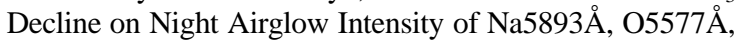
$\mathrm{OH}$ Emission and Its Correlation with Solar Flare Numbers,” Earth, Moon \& Planets (The Netherlands), Vol. 61, No. 2, 1993, pp. 175-182. doi:10.1007/BF00572412

[5] S. K. Midya and R. Chattopadhyay, "Evening TwilightGlow of Sodium 5893 A Line Emission at Calcutta and Its Typical Relation with Astronomical Parameters," Indian Journal of Radio \& Space Physics, Vol. 35, No. 2, 2006, pp. 77-83.

[6] J. W. Chamberlain, "Physics of the Aurora and Airglow," Academic Press, New York, 1961.

[7] D. M. Hunten, “Airglow Introduction and Review,” In: B. M. McCormac, Ed., The Radiating Atmosphere, D. Reidel Publishing Company, Dordrecht, 1970, pp. 1-16.

[8] T. N. Davis, “The Night Airglow,” 1979, Article \#293. http://www.gi.alaska.edu/ScienceForum/ASF2/293.html

[9] A. Taori, A. Jayaraman, K. Raghunath and V. Kamalakar, "A New Method to Derive Middle Atmospheric Temperature Profiles Using a Combination of Rayleigh Lidar and $\mathrm{O}_{2}$ Airglow Temperatures Measurements," Annals of Geophysics, Vol. 30, No. 1, 2012, pp. 27-32. doi:10.5194/angeo-30-27-2012

[10] H. Gao, J.-B. Nee and J. Xu, "The Emission of Oxygen Green Line and Density of O Atom Determined by Using ISUAL and SABER Measurements," Annals of Geophysics, Vol. 30, No. 4, 2012, pp. 695-701. doi:10.5194/angeo-30-695-2012

[11] T. Bangia, S. Bhattacharjee, A. Guharay, A. Taori and W. Uddin, "Study of Upper Atmospheric Emissions Using Mesosphere Lower Thermosphere Photometer (MLTP) Designed at ARIES," Indian Journal of Radio \& Space Physics, Vol. 39, No. 5, 2010, pp. 325-329.

[12] D. R. Bates, "Excitation of 557.7 nm OI Line in Night-
Glow," Planetary and Space Science, Vol. 36, No. 9, 1988, pp. 883-889. doi:10.1016/0032-0633(88)90094-3

[13] C. A. Barth and A. F. Hildebrandt, "The 5577 A Airglow Emission Mechanism,” Journal of Geophysical Research, Vol. 66, No. 3, 1961, pp. 985-986.

[14] T. Ogawa, N. Balan, Y. Otsuka, K. Shiokawa, C. Ihara, T. Shimomai and A. Saito, "Observations and Modeling of $630 \mathrm{~nm}$ Airglow and Total Electron Content Associated with Traveling Ionospheric Disturbances over Shigaraki, Japan,” Earth, Planet Space (Japan), Vol. 54, No. 1, 2002, pp. 45-56.

[15] J. Sobral, M. Abdu, H. Takahashi, M. Taylor, E. de Paula, C. Zamlutti, M. de Aquino and G. Borba, "Ionospheric Plasma Bubble Climatology over Brazil Based on 22 Years (1977-1998) of $630 \mathrm{~nm}$ Airglow Observations,” Journal of Atmospheric and Solar-Terrestrial Physics (UK), Vol. 64, No. 1214, 2002, pp. 1517-1524. doi:10.1016/S1364-6826(02)00089-5

[16] P. K. Jana and S. C. Nandi, "Effect of Solar Parameters on Antarctic, Arctic and Tropical Ozone during the Last Solar Cycle,” Indian Journal of Radio \& Space Physics, Vol. 34, No. 2, 2005, pp. 114-118.

[17] P. K. Jana and S. C. Nandi, "Depletion of Ozone and Its Effect on Night Airglow Intensity of Na $5893 \AA$ at New Delhi $\left(29^{\circ} \mathrm{N}, 77^{\circ} \mathrm{E}\right)$ and Halley Bay $\left(76^{\circ} \mathrm{S}, 27^{\circ} \mathrm{W}\right), ”$ Indian Journal of Physics, Vol. 79, No. 11, 2005, pp. 1113-1317.

[18] P. K. Jana and S. C. Nandi, "Depletion of Ozone and Its Effect on Night Airglow Intensity of $\mathrm{Na} 5893 \AA$ at Trivandrum $\left(8.25^{\circ} \mathrm{N}, 76.9^{\circ} \mathrm{E}\right)$ and Halley Bay $\left(76^{\circ} \mathrm{S}\right.$, $\left.27^{\circ} \mathrm{W}\right)$," Mausam, Vol. 57, No. 2, 2005, pp. 350-354.

[19] P. K. Jana and S. C. Nandi, “Ozone Decline and Its Effect on Night Airglow Intensity of Na $5893 \AA$ at Dumdum $\left(22.5^{\circ} \mathrm{N}, 88.5^{\circ} \mathrm{E}\right)$ and Halley Bay $\left(76^{\circ} \mathrm{S}, 27^{\circ} \mathrm{W}\right), "$ Journal of Earth System Science, Vol. 115, No. 5, 2006, pp. 607613. doi:10.1007/BF02702913

[20] P. K. Jana, I. Saha, P. Das, D. Sarkar and S. K. Midya, "Long-Term Ozone Trend and Its Effect on Night Airglow Intensity of Li $6708 \AA$ at Ahmedabad $\left(23^{\circ} \mathrm{N}, 72.5^{\circ} \mathrm{E}\right)$, India and Halley Bay $\left(76^{\circ} \mathrm{S}, 27^{\circ} \mathrm{W}\right)$, British Antarctic Service Station,” Indian Journal of Physics, Vol. 84, No. 1, 2010, pp. 41-53. doi:10.1007/s12648-010-0003-5

[21] B. M. Vyas and V. Saraswat, "Long Term Trend in Nocturnal Airglow Emission of $589.3 \mathrm{~nm}$ over Mid Latitude Japanese Station i.e., Kiso $\left(35.79^{\circ} \mathrm{N}, 137.63^{\circ} \mathrm{E}\right), ” 2012$. http://www.nipne.ro/rjp/accpaps/Saraswat_V_8FB31B.pd f).

[22] G. Beig, P. Keckhut, R. P. Lowe, R. G. Roble, M. G. Mlyczak, J. Scheer, V. I. Fomichev, D. Offerman, W. J. R. French, M. G. Shepherd, A. I. Semenov, E. E. Remsberg, C. Y. She, F. J. Lubken, J. Bremer, B. R. Clemesha, J. Stegman, F. Sigernes and S. Fadnavis, "Review of Mesospheric Temperature Trends," Reviews of Geophysics, Vol. 41, No. 4, 2003, pp. 1-41. doi:10.1029/2002RG000121

[23] P. K. Rajesh, J. Y. Liu, H. S. S. Sinha, S. B. Banerjee, R. N. Misra, N. Dutt and M. B. Dadhania, "Observations of Plasma Depletions in 557.7 nm Images over Kavalur," Journal of Geophysical Research, Vol. 112, 2007. doi:10.1029/2006JA012055 
[24] U. Das and H. S. S. Sinha, "Long Term Variations in Oxygen Green Line Emission over Kiso, Japan from Ground Photometric Observations Using Continuous Wavelet Transform,” Journal of Geophysical Research, Vol. 113, 2008. doi:10.1029/2007JD009516

[25] U. Das, C. J. Pan and H. S. S. Sinha, "Effects of Solar Cycle Variations on Oxygen Green Line Emission Rate over Kiso, Japan,” Earth Planets Space, Vol. 63, No. 8, 2011, pp. 941-948.

[26] R. L. Carovillano and J. M. Forbes, "Solar Terrestrial Physics, Principles and Theoretical Foundations," D. Reidel Publishing Company, Dordrecht, 1983. 